\title{
PAPER
}

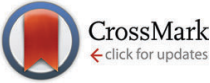

Cite this: Phys. Chem. Chem. Phys., $2015,17,5124$

Received 8th November 2014

Accepted 7th January 2015

DOI: $10.1039 / c 4 c p 05179 c$

www.rsc.org/pccp

\section{LEIS and XPS investigation into the growth of cerium and cerium dioxide on $\mathrm{Cu}(111)$}

\author{
G. Vári, ${ }^{a}$ L. Óvári, ${ }^{* b}$ J. Kiss ${ }^{b}$ and Z. Kónya ${ }^{a b}$
}

The controlled growth of $\mathrm{Ce}$ and $\mathrm{CeO}_{2}$ on $\mathrm{Cu}(111)$ was investigated applying low energy ion scattering spectroscopy (LEIS) and X-ray photoelectron spectroscopy (XPS). Previous LEIS studies on metallic and oxidised cerium deposits using other metallic substrates reported serious difficulties related to the neutralization of noble gas ions. For this reason, special attention was paid here to reveal possible matrix effects for the neutralization ("neutralization effects"), which would severely hinder quantitative evaluation of the LEIS data. The adsorption of $\mathrm{O}_{2}$ on $\mathrm{Cu}(111)$ induced no neutralization effects either with $\mathrm{He}^{+}$or $\mathrm{Ne}^{+}$. Similarly, no neutralization effects were identified using $\mathrm{He}^{+}$upon the deposition of metallic $\mathrm{Ce}$ on $\mathrm{Cu}(111)$, but it arises for the Ce peak monitored with $\mathrm{Ne}^{+}$. The initial growth of $\mathrm{Ce}$ is two dimensional up to $\Theta_{\mathrm{Ce}} \sim 0.5 \mathrm{ML}$, while almost complete coverage of $\mathrm{Cu}(111)$ is achieved at $\Theta_{\mathrm{Ce}}=2 \mathrm{ML}$. $\mathrm{CeO}_{2}(111)$ was deposited evaporating $\mathrm{Ce}$ in a background of $\mathrm{O}_{2}$ at a sample temperature of $523 \mathrm{~K}$. No neutralization effects were observed either with $\mathrm{He}^{+}$or $\mathrm{Ne}^{+}$. In harmony with literature data, the growth mode is three dimensional. Here it was demonstrated that the continuity of the film, which could be efficiently checked by LEIS, is influenced by the applied oxygen pressure in the range of $5 \times 10^{-7}-3 \times 10^{-6} \mathrm{mbar}$. At $p_{\mathrm{O}_{2}}=3 \times 10^{-6} \mathrm{mbar}$ the film was not completely closed even at relatively large coverages $(16 \mathrm{ML})$, and a significant part of copper atoms were oxidized to $\mathrm{Cu}^{1+}$. Deposition of $\mathrm{CeO}_{2}$ at $p_{\mathrm{O}_{2}}=5 \times 10^{-7}$ mbar was characterized by a nearly perfect wetting, with metallic copper atoms at the interface, and with a slightly more reduced ceria layer.

\section{Introduction}

Cerium dioxide $\left(\mathrm{CeO}_{2}\right)$ is an efficient support or promoter in many catalytic reactions, such as automotive exhaust catalysis, water gas shift reaction (WGS), steam reforming of ethanol (SRE), catalytic removal of $\mathrm{SO}_{x}$, electrochemical oxidation of hydrocarbons, etc. ${ }^{1-7}$ Most importantly, since it is easily reducible to $\mathrm{Ce}_{2} \mathrm{O}_{3}$, it can act as an oxygen buffer. Apart from this aspect, its basic character is it can also play a role in catalytic transformations.

For a deeper understanding of surface processes during complicated catalytic reactions, it is useful to construct simplified, but well controlled experimental model systems, using oxide single crystals or single crystalline oxide films, and to prepare nanoclusters of the active metal on top. ${ }^{8-13}$ The low conductivity of $\mathrm{CeO}_{2}$ single crystals (e.g. compared to that of $\mathrm{TiO}_{2}$ ) motivated an intense research aiming at the preparation of ultrathin single crystalline films of $\mathrm{CeO}_{2}$ using various metallic supports, such as $\mathrm{Ru}(0001),{ }^{14,15} \mathrm{Cu}(111),{ }^{16-23} \operatorname{Pd}(111)^{24}$ etc.

\footnotetext{
${ }^{a}$ Department of Applied and Environmental Chemistry, University of Szeged, Rerrich Béla tér 1., Szeged, H-6720, Hungary

${ }^{b}$ MTA-SZTE Reaction Kinetics and Surface Chemistry Research Group,

Rerrich Béla tér 1., Szeged, H-6720, Hungary.E-mail: ovari@chem.u-szeged.hu
}

Since the interaction of oxygen and the support metal single crystal is an important characteristic of these systems, it is useful to briefly summarize here the related previous results, focussing on $\mathrm{Cu}(111)$, the substrate used in the present study. The adsorption of $\mathrm{O}_{2}$ on $\mathrm{Cu}(111)$ was thoroughly investigated in the pressure range of $\sim 1 \times 10^{-6}$ mbar at both $300 \mathrm{~K}$ and elevated temperatures. $^{23,25-29}$ It was demonstrated by STM that oxygen is capable of abstracting $\mathrm{Cu}$ from the terraces at room temperature, starting from the step edges and vacancy sites. ${ }^{29}$ A surface oxide forms at $300 \mathrm{~K}$ with a structure close to $\mathrm{Cu}_{2} \mathrm{O}(111)$, though containing many defects. ${ }^{29}$ Extended areas of the so called " 44 " structure $\left(\sqrt{73} R 5.8^{\circ} \times \sqrt{21} R-10.9^{\circ}\right)$ can be produced performing the oxidation at higher temperatures $(423-600 \mathrm{~K}){ }^{23,29}$ This structure originates from a distorted $\mathrm{Cu}_{2} \mathrm{O}(111)$-like layer grown epitaxially on the $\mathrm{Cu}(111)$ substrate. The $\mathrm{Cu}_{2} \mathrm{O}(111)$-like " 44 " layer possesses the same honeycomb structure as the $\mathrm{Cu}_{2} \mathrm{O}(111)$ surface, but with the coordinatively under-saturated $\mathrm{Cu}$ atoms (cus-Cu) removed. ${ }^{23,27-30}$ Annealing the " 44 " structure in a UHV at 573-673 K led to the transformation of the surface into the " 29 " structure. ${ }^{29}$ The formation of the " 29 " structure $\left(\sqrt{13} R 46.1^{\circ} \times 7 R 21.8^{\circ}\right)$ was also reported after oxidation $(\sim 7 \times$ $10^{-7} \mathrm{mbar}_{2}$ ) at $700-750 \mathrm{~K}^{23}$ In the "29" surface oxide the hexagonal structure associated with $\mathrm{Cu}_{2} \mathrm{O}(111)$ is more distorted; it contains $0.52 \mathrm{ML}$ (monolayer) of $\mathrm{O}$. Further oxidation of 
$\mathrm{Cu}(111)$ is not possible at $p<10^{-5}$ mbar (up to $\sim 2000 \mathrm{~L}$, $1 \mathrm{~L}=10^{-6}$ Torr $\left.\times 1 \mathrm{~s}\right) \cdot{ }^{27,28}$

$\mathrm{CeO}_{2}(111)$ layers were previously prepared either depositing Ce in an $\mathrm{O}_{2}$ atmosphere $\left(2 \times 10^{-7}-1 \times 10^{-6}\right.$ mbar $)$ or evaporating Ce in ultrahigh vacuum (UHV), followed by an oxidation step. The deposition temperature also varied (100-723 K, in some cases applying heating ramps during deposition), but a high temperature treatment (at $T \geq 520 \mathrm{~K}$ in $\sim 5 \times 10^{-7} \mathrm{mbar}_{2}$ ) was always required to obtain a well ordered film. ${ }^{16-23}$ There is general agreement that the $\mathrm{CeO}_{2}(111) / \mathrm{Cu}(111)$ system thermodynamically follows the Volmer-Weber (3D) growth mode, probably due to the weak interaction between the oxide and the support. ${ }^{19,20}$ Investigation of the initial growth of $\mathrm{CeO}_{2}(111)$ on $\mathrm{Cu}(111)$ revealed that the dissociation of $\mathrm{O}_{2}$ is facilitated by the presence of $\mathrm{CeO}_{2}$ nanoparticles, and there is a spill-over of oxygen to the copper. ${ }^{23}$ While in some cases the presence of extra spots in the LEED structure or the observed periodicities in (overlapping) moiré patterns led some authors to hypothesize oxygen induced reconstructions of the interfacial copper layer, ${ }^{19,23}$ in other cases it was assumed that the $\mathrm{CeO}_{2}(111)$ layer replaces surface copper oxides. ${ }^{20}$ The most frequently applied recipe for the preparation of continuous $\mathrm{CeO}_{2}$ (111) layers consists of the deposition of Ce in an $\mathrm{O}_{2}$ background of $\sim 5 \times 10^{-7}$ mbar at $523 \mathrm{~K}$ at a rate of $0.08-0.15 \mathrm{ML} \mathrm{min}{ }^{-1} .1 \mathrm{ML}$ of the $\mathrm{CeO}_{2}(111)$ layer is defined as one $\mathrm{O}-\mathrm{Ce}-\mathrm{O}$ trilayer of the fluorite structure of bulk $\mathrm{CeO}_{2}$ (3.13 $\AA$ ). This method yields a well oriented, but corrugated film with relatively small terraces $(10 \mathrm{~nm}) .^{20,21}$ There is a slight uncertainty in the literature regarding the minimum coverage required to obtain a continuous film with this recipe. While in ref. 18 the 2.5 ML thick film was found to be continuous, based on the complete disappearance of the $\mathrm{Cu}(111)$ LEED pattern, in other cases ${ }^{19}$ even at $5 \mathrm{ML}$ the film was still slightly incomplete (LEED, STM). Traces of $\mathrm{Cu}(\sim 0.002 \mathrm{ML})$ on the outermost atomic layer were detected even for $\sim 10 \mathrm{ML}$ of $\mathrm{CeO}_{2}{ }^{31}$ For model catalytic studies, the continuity of the film is important to avoid direct contact of reactants with the metal single crystal substrate. In the present study low energy ion scattering (LEIS) was used to monitor in situ the tightness of the ceria film. Since this method provides information almost exclusively about the outermost atomic layer, when performed with noble gas ions, ${ }^{32}$ it is particularly suited for this purpose.

Although the adsorption of metallic $\mathrm{Ce}$ on $\mathrm{Cu}(111)$ is also important for a complete understanding of the preparation of ceria nanolayers on $\mathrm{Cu}(111)$, related literature data are rather scarce. The deposition of Ce metal on a $\mathrm{Cu}$ film at $300 \mathrm{~K}$ led to significant intermixing of $\mathrm{Ce}$ and $\mathrm{Cu}^{33}$ The bulk solubility of Ce in $\mathrm{Cu}$ and $\mathrm{Cu}$ in $\mathrm{Ce}$ is very limited, below 0.4 at\% in our temperature range $(T \leq 900 \mathrm{~K})$, but several copper-cerium intermetallic compounds exist: $\mathrm{Cu}_{6} \mathrm{Ce}, \mathrm{Cu}_{5} \mathrm{Ce}, \mathrm{Cu}_{4} \mathrm{Ce}, \mathrm{Cu}_{2} \mathrm{Ce}$, and CuCe. ${ }^{34}$ The loss of material $\left(\mathrm{CeO}_{2}\right.$ average thickness $)$ observed during repeated annealing of $\mathrm{CeO}_{2}(111)$ films on $\mathrm{Cu}(111)$ up to $823 \mathrm{~K}$ was attributed to the diffusion of Ce into the bulk. ${ }^{19}$

Since no systematic LEIS study appeared so far about the deposition of $\mathrm{Ce}$ and $\mathrm{CeO}_{2}$ on $\mathrm{Cu}(111)$, it seemed to us worthwhile to investigate this system in detail, completed by X-ray photoelectron spectroscopy (XPS). The intensity of an ion scattering peak depends sensitively on the neutralization probability for the impinging noble gas ions upon the collision with the surface atoms. ${ }^{32}$ Although matrix effects for the neutralization probability (i.e. changes in the neutralization during scattering on the given atom as a function of its chemical environment), sometimes simply referred to as "neutralization effects", are relatively rare in LEIS, these can severely hinder a quantitative evaluation of the data, if they arise. ${ }^{32}$ For this reason special attention was paid in this study to neutralization effects. Note that previous LEIS studies, devoted to the deposition of Ce on other metal surfaces, reported serious difficulties. The Ce LEIS peak was not detectable at all with $\mathrm{He}^{+}$on $\mathrm{Rh}(111)$ and it was very weak with $\mathrm{Ne}^{+}$. Moreover, significant changes in the neutralization probabilities were observed with both projectiles. ${ }^{35}$ After the deposition (and oxidation) of Ce on $\operatorname{Pd}(111)$ at room temperature, the $\mathrm{Pd}$ LEIS peak decreased rapidly, but no Ce peak could be observed by LEIS using He ions, attributed mostly to the large neutralization probability of $\mathrm{He}^{+}$, possibly due to quasi resonant neutralization. ${ }^{24}$ However, with $\mathrm{Ne}^{+}$the Ce peak was easily detectable. A slight attenuation of the neutralization probability of $\mathrm{Ne}^{+}$(on Ce) was observed due to $\mathrm{O}_{2}$ adsorption.

\section{Experimental}

The experiments were carried out in a UHV chamber with a base pressure of $5 \times 10^{-10}$ mbar. It was equipped with a Leybold hemispherical analyser for performing LEIS, XPS, and Auger electron spectroscopy (AES) measurements. For LEIS a constant retardation ratio was applied, while XPS was performed with a constant pass energy. A quadrupole mass spectrometer (QMS) was used in this work for rest gas analysis. A SPECS IQE 12/38 ion source was used for LEIS. $\mathrm{He}^{+}$or $\mathrm{Ne}^{+}$ions with $800 \mathrm{eV}$ kinetic energy were applied at a low ion flux, $\sim 0.03 \mu \mathrm{A} \mathrm{cm}{ }^{-2}$. The incident and detection angles were $50^{\circ}$ (with respect to the surface normal), while the scattering angle was $95^{\circ}$. The angle between the "incident plane" (the plane defined by the ion source axis and the surface normal) and the "detection plane" (the plane defined by the surface normal and the analyzer axis) was $53^{\circ}$. An $\mathrm{Al} \mathrm{K} \alpha$ X-ray source was applied for XPS. The binding energy scale was calibrated against the $4 f_{7 / 2}$ peak of a thick Au layer $(84.0 \mathrm{eV})$ and the $2 \mathrm{p}_{3 / 2}$ peak of the clean $\mathrm{Cu}(111)$ surface $(932.6 \mathrm{eV})$. The detection angle was $16^{\circ}$ off normal. Peak fitting of the Ce $3 \mathrm{~d}$ XPS region and of the LEIS spectra obtained with helium was executed with the help of XPSPEAK 4.1 using Gauss-Lorentzian sum line shapes and Shirley baselines. ${ }^{36}$ For LEIS and in some cases for the Ce 3d XPS region asymmetry was also allowed applying an exponential tailing function.

The $\mathrm{Cu}(111)$ single crystal was a product of MaTeck (purity: 99.9999\%, orientation accuracy: $\left.0.1^{\circ}\right)$. Its temperature was measured by a chromel-alumel (K-type) thermocouple inserted into a hole in the crystal. It was heated radiatively with a $\mathrm{W}$ filament placed behind the crystal. The surface was routinely cleaned applying cycles of $\mathrm{Ar}^{+}$ion sputtering $\left(10 \mu \mathrm{A} \mathrm{cm}{ }^{-2}\right.$, $1.5 \mathrm{keV}$ ) at $300 \mathrm{~K}$ and vacuum annealing ( $5 \mathrm{~min}, 1000 \mathrm{~K}$ ).

The purity of $\mathrm{O}_{2}$ (Linde) was $99.995 \%$. One monolayer of $\mathrm{O}$ is defined as the surface concentration of $\mathrm{Cu}(111)$ 
$\left(1.78 \times 10^{15}\right.$ atoms per $\left.\mathrm{cm}^{2}\right)$. Ce (99.9\%) was deposited by a commercial 4-pocket PVD source (Oxford Applied Research) using a Ta crucible. One monolayer of $\mathrm{CeO}_{2}$ is defined as a complete $\mathrm{CeO}_{2}(111)$ trilayer (i.e., O-Ce-O stack, $7.87 \times 10^{14} \mathrm{Ce}$ atoms per $\mathrm{cm}^{2}$ ) having a thickness of $3.13 \AA^{37}$ The phase diagram of metallic Ce contains three phases under moderate conditions ( $T<1000 \mathrm{~K}, p<3 \mathrm{GPa}): \alpha(\mathrm{fcc}), \beta$ (dhcp), and $\gamma(\mathrm{fcc}) .{ }^{38}$ For metallic $\mathrm{Ce}$, here we define the one ML coverage as the surface concentration of the close packed (0001) surface of the dhcp bulk $\beta$ phase, because it is the thermodynamically stable phase at room temperature. In this way $1 \mathrm{ML}$ of $\mathrm{Ce} \sim 8.53 \times 10^{14} \mathrm{~cm}^{-2} \cdot{ }^{37}$ Although in terms of Ce surface concentration there is a small difference in the coverage scale for $\mathrm{Ce}$ and $\mathrm{CeO}_{2}$, we choose these definitions, because in the case of layer-by-layer growth complete coverage of the $\mathrm{Cu}(111)$ surface is achieved at $1 \mathrm{ML}$ in both cases. The coverage of Ce was checked by a quartz crystal microbalance (QCM), and the evaporation rate was $0.07 \mathrm{ML}$ per min for both $\mathrm{Ce}$ and $\mathrm{CeO}_{2}$.

\section{Results and discussion}

Since in previous LEIS studies on the adsorption of Ce on $\mathrm{Rh}(111)$ and $\operatorname{Pd}(111)$ neutralization effects arose ${ }^{24,35}$ this issue was carefully checked in the present work. The charge transfer between surface atoms and the noble gas projectile can proceed according to different mechanisms. ${ }^{32}$ Resonant neutralization (RN) occurs, when an electron from the highest lying (partly) filled valence (conduction) band of the target tunnels into an empty excited level of the projectile. If a deeper filled band of the solid is aligned with the 1 s level of the projectile, then a resonant electron transfer can proceed in a similar way. Since this alignment is generally not perfect, this process is called quasi resonant neutralization (qRN). Electrons from the high lying conduction-valence band of the solid can be transferred to the $1 \mathrm{~s}$ level of the projectile, if the energy released in this step is transferred to an Auger electron from the target. This Auger neutralization (AN) mechanism is operative in every case, though resonant processes typically dominate, if they arise. If the primary ion energy exceeds a threshold, and consequently the minimum distance between the surface nucleus and the ion is small enough then new neutralization channels open (collision induced neutralization, CIN). Reionization processes can play a significant role as well, influencing both the background of the spectrum and the single scattering peak. ${ }^{32}$

If there are no neutralization matrix effects for the system consisting of elements A and B, then the observed intensity for A $\left(I_{\mathrm{A}}\right)$ is a linear function of that of $\mathrm{B}\left(I_{\mathrm{B}}\right)$, when the surface composition is varied, if the geometrical shadowing effect of a deposited atom does not change with coverage. The control of this behaviour is a widely used check for the occurrence of neutralization effects. ${ }^{32,39}$ This method was applied also in the present study.

\section{The adsorption of $\mathrm{O}_{2}$ on $\mathrm{Cu}(111)$}

Although the adsorption of $\mathrm{O}_{2}$ on $\mathrm{Cu}(111)$ was previously investigated in detail, as summarized in the Introduction, it seemed to us necessary to perform some measurements on the
$\mathrm{O} / \mathrm{Cu}(111)$ system focussing on possible neutralization effects. It serves mostly for comparison with the $\mathrm{CeO}_{2} / \mathrm{Cu}(111)$ surface. $\mathrm{O}_{2}$ was dosed for $5 \mathrm{~min}$ on the $\mathrm{Cu}(111)$ surface at $300 \mathrm{~K}$, at pressures increased stepwise. Surface oxygen was not removed in between the adsorption steps. LEIS spectra, obtained in this measurement with He, are displayed in Fig. 1(a). The peak areas (using $\mathrm{He}$ and $\mathrm{Ne}$ ) and the pressure applied for the last adsorption step are shown in Fig. 1(b) as a function of the cumulative $\mathrm{O}_{2}$ exposure, measured in $\mathrm{L}\left(1 \mathrm{~L}=10^{-6}\right.$ Torr $\mathrm{s}$, 1 Torr $=1.33$ mbar).

The small peak observed at $\sim 507 \mathrm{eV}$ is not due to surface contamination (the cleanliness of the $\mathrm{Cu}(111)$ surface was controlled also by XPS and AES), but can be assigned to an instrumental artifact: the ion source produced a small quantity of $\mathrm{He}^{+}$ions with a kinetic energy of $\mathrm{e} U_{\mathrm{f}}$, where $U_{\mathrm{f}}$ is the potential of the focussing electrode. These ions were also scattered on the surface $\mathrm{Cu}$ atoms, resulting in a distinct peak at a position, which scaled appropriately with the focus voltage, while keeping the primary energy on the ion supply constant. The intensity of this "ghost" peak was $\sim 0.4 \%$ of that of the main peak. This contribution was removed via peak fitting during the quantitative evaluation of the $\mathrm{O}$ peak.

In parallel with the enhancement of the $\mathrm{O}$ LEIS area obtained with $\mathrm{He}$ (denoted $\mathrm{O}(\mathrm{He})$ ) due to the accumulation of $\mathrm{O}$ on the surface, the copper peaks obtained with helium $(\mathrm{Cu}(\mathrm{He}))$ and neon $(\mathrm{Cu}(\mathrm{Ne}))$ decreased. This process reached a saturation at $\sim 400 \mathrm{~L}$ (Fig. 1(b)), in accordance with a previous LEIS study on $\mathrm{O}_{2} / \mathrm{Cu}(111) .{ }^{40}$ Since in ref. 40 the occurrence of neutralization effects was not addressed in detail, the linearity of the $\mathrm{Cu}-\mathrm{O}$ curve was analysed here. As displayed in Fig. 1(c), the $\mathrm{Cu}(\mathrm{He})$ area decreased linearly with the increase of the $\mathrm{O}(\mathrm{He})$ signal. This implies that the $\mathrm{O}$ coverage is proportional to the $\mathrm{O}(\mathrm{He})$ LEIS signal, and each adsorbed oxygen atom attenuates the $\mathrm{Cu}(\mathrm{He})$ signal on average to the same extent, allowing the quantitative evaluation of the data. The above statement holds for the shadowing of the copper surface by oxygen also using neon, since the $\mathrm{Cu}(\mathrm{Ne})$ vs. $\mathrm{O}(\mathrm{He})$ curve was also linear (Fig. 1(c)). Consequently, the $\mathrm{Cu}(\mathrm{Ne})$ vs. $\mathrm{Cu}(\mathrm{He})$ curve, corresponding to the $\mathrm{O}_{2}$ adsorption experiment, was also linear (Fig. 1(d)). However, this latter straight line does not pass through the origin, or in other words, the adsorption of oxygen attenuates the $\mathrm{Cu}(\mathrm{He})$ peak more steeply than the $\mathrm{Cu}(\mathrm{Ne})$ peak. The shielding effect of oxygen is stronger, when helium is used. Since LEIS spectra with $\mathrm{He}^{+}$were recorded before spectra with $\mathrm{Ne}^{+}$, one might argue that this effect is an artifact, and the intercept of the linear in Fig. 1(d) with the vertical axis is influenced by the sputtering effect of $\mathrm{Ne}^{+}$ions. However, this is not the case, since the repetition of the experiment with 5 times higher $\mathrm{Ne}^{+}$flux gave qualitatively similar results and the slope in Fig. 1(d) was attenuated only by $14 \%$.

For the understanding of the differences in the shielding effect of oxygen with helium and neon, it is worth considering that during the scattering of $\mathrm{He}^{+}$ions on adsorbed $\mathrm{O}$ atoms a so called shadow cone is formed behind the $\mathrm{O}$ nuclei, where the projectile cannot penetrate. ${ }^{32}$ It is not the case for $\mathrm{Ne}$ ions, which are heavier than $\mathrm{O}$, and can reach $\mathrm{Cu}$ atoms behind $\mathrm{O}$. 

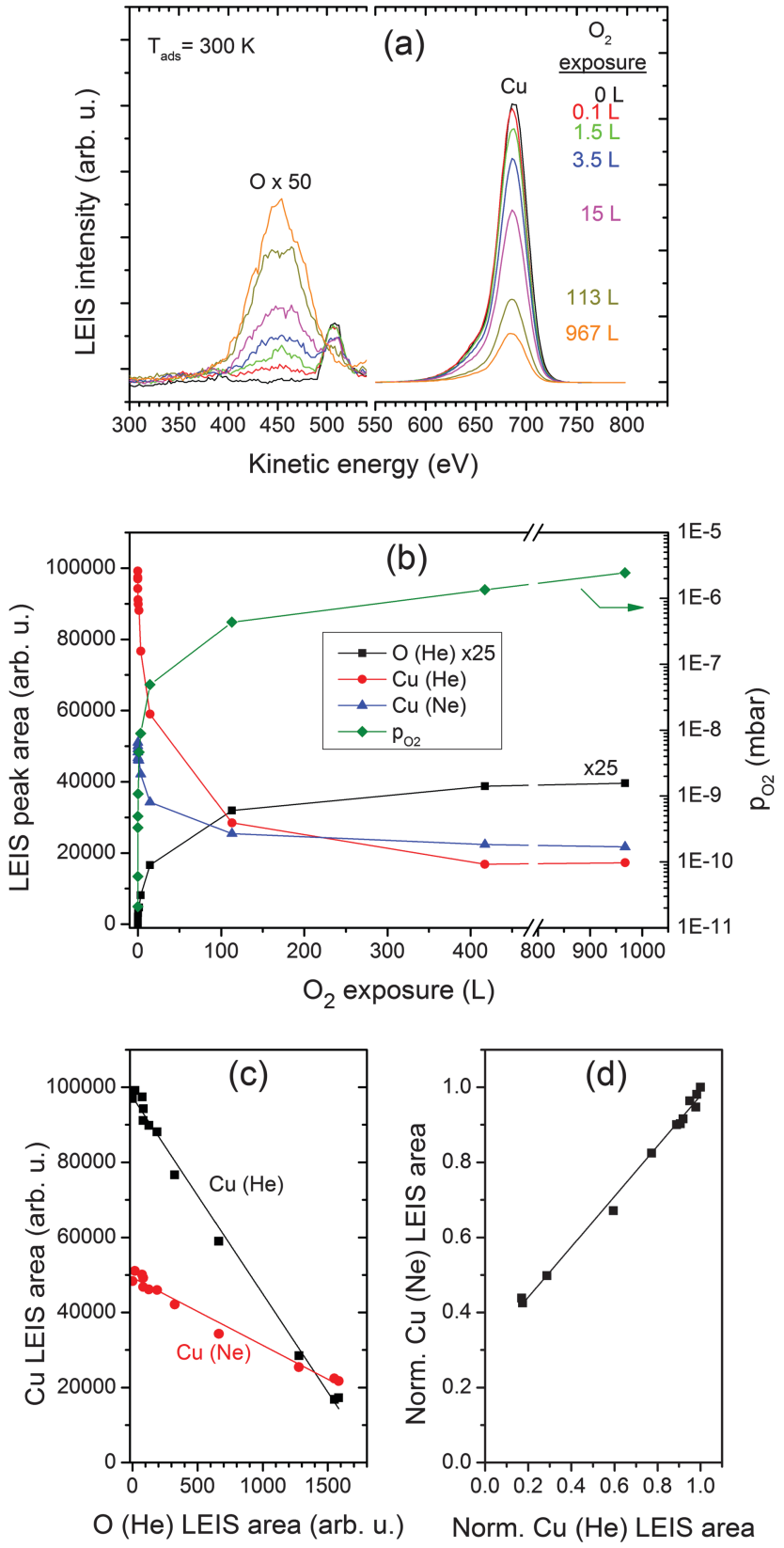

Fig. 1 (a) LEIS spectra obtained after exposing the $\mathrm{Cu}(111)$ surface at $300 \mathrm{~K}$ to $\mathrm{O}_{2}$ at stepwise increased pressures for $5 \mathrm{~min}$ each. The surface oxygen was not removed in between the adsorption steps. The cumulative $\mathrm{O}_{2}$ exposure is shown beside each spectrum. (b) LEIS peak areas (of $\mathrm{O}$ and $\mathrm{Cu}$ using $\mathrm{He}$, and of $\mathrm{Cu}$ using $\mathrm{Ne}$ ) obtained in the measurement described for (a). For each $\mathrm{O}_{2}$ adsorption step the applied pressure is also shown as a function of the cumulative oxygen exposure (vertical scale on the right). (c) Copper LEIS peak areas obtained with $\mathrm{He}$ and $\mathrm{Ne}$ in the measurement described for (a) displayed as a function of the O LEIS peak area obtained with $\mathrm{He}$. (d) The Cu peak area obtained with $\mathrm{Ne}$ as a function of the $\mathrm{Cu}$ area detected with $\mathrm{He}$.

Nevertheless, copper atoms are partly shadowed by oxygen also using neon for two reasons: (i) there is a deviation of $\mathrm{Ne}^{+}$ions by $\mathrm{O}$ anyhow; (ii) only those neon trajectories contribute to the $\mathrm{Cu}$ peak, which correspond to single scattering events, i.e. when there is no significant impact with oxygen. For double and multiple scattering the neutralization is generally too efficient for that event to be observed, and in case it is detectable, the peak energy is different from the single scattering peak. ${ }^{32}$ Note that it was previously demonstrated that neutralization does not solely happen in the close vicinity of the target surface atom, but also when the noble gas ion travels by neighbouring atoms (trajectory dependent neutralization), modifying also the intensity of the single scattering peak, such as for $\mathrm{O} / \mathrm{Ni}(100)$, $\mathrm{O} / \mathrm{Cu}(100)$ and $\mathrm{Pb}(111) .{ }^{41-43}$ This process can operate to a different extent for He and Ne. Although this phenomenon, strictly speaking, is a neutralization effect, it does not necessarily impede a quantitative analysis. It was suggested that a shell-like neutralization region is operative around neighbouring nuclei, ${ }^{43}$ which in a certain sense can be considered a modification of the size of the shadow cone of neighbour atoms. Although we cannot exclude a similar effect in our case, the linear behaviour presented in Fig. 1(c) proves that quantitative information can be extracted from our data. Due to the differences in the scattering of $\mathrm{He}^{+}$and $\mathrm{Ne}^{+}$on $\mathrm{O} / \mathrm{Cu}(111)$ mentioned above, it is not expected that the diminution of the Cu LEIS peak induced by the same amount of adsorbed $\mathrm{O}$ is identical for the two noble gases.

The linear dependence of the $\mathrm{Cu}(\mathrm{He})$ area on the $\mathrm{O}(\mathrm{He})$ area can be written as

$$
A_{\mathrm{Cu}}=A_{\mathrm{Cu}}(0)-A_{\mathrm{O}} / S_{\mathrm{O}},
$$

where $A_{\mathrm{Cu}}$ and $A_{\mathrm{O}}$ are the $\mathrm{Cu}(\mathrm{He})$ and $\mathrm{O}(\mathrm{He})$ areas, while $A_{\mathrm{Cu}}(0)$ is the $\mathrm{Cu}(\mathrm{He})$ area of the clean copper surface. This can be transformed into

$$
\zeta_{\mathrm{Cu}}+\zeta_{\mathrm{O}}=1,
$$

where $\zeta_{\mathrm{Cu}}=A_{\mathrm{Cu}} / A_{\mathrm{Cu}}(0)$ and $\zeta_{\mathrm{O}}=A_{\mathrm{O}} /\left(A_{\mathrm{Cu}}(0) \times S_{\mathrm{O}}\right)$ are the fractions of the surface covered by $\mathrm{Cu}$ and $\mathrm{O}$, respectively. $S_{\mathrm{O}}$ is the relative sensitivity factor for $\mathrm{O}$, which can be obtained as the reciprocal slope of the $\mathrm{Cu}(\mathrm{He}) v s$. $\mathrm{O}(\mathrm{He})$ curve. $S_{\mathrm{O}}=0.0191$ under our circumstances.

The saturation $\mathrm{O}$ coverage was estimated also from the $\mathrm{O} 1 \mathrm{~s}$ and $\mathrm{Cu} 2 \mathrm{p}$ XPS areas obtained after exposing the $\mathrm{Cu}(111)$ surface to $3 \times 10^{-6} \mathrm{mbar}_{2}$ for $5 \mathrm{~min}$ at $300 \mathrm{~K}(680 \mathrm{~L})$. The application of standard inelastic-mean-free-path (imfp) and photoelectric cross section values yielded $\Theta_{\mathrm{O}}=0.76 \pm 0.1 \mathrm{ML}^{44,45}$ Since saturation with $\mathrm{O}$ attenuated the $\mathrm{Cu}(\mathrm{He})$ LEIS peak by $83 \%$, it can be concluded that one surface $\mathrm{O}$ atom shadows approximately one $\mathrm{Cu}$ atom in ion scattering experiments performed with $\mathrm{He}$, under our experimental conditions.

\section{The growth of $\mathrm{Ce}$ on $\mathrm{Cu}(111)$}

As a next step, the growth of $\mathrm{Ce}$ on $\mathrm{Cu}(111)$ was investigated at 300 K. In Fig. 2 LEIS spectra obtained with $\mathrm{He}$ and $\mathrm{Ne}$ are shown after depositing Ce on the $\mathrm{Cu}(111)$ surface at $300 \mathrm{~K}$. Each dose of Ce was evaporated on the clean $\mathrm{Cu}$ surface. The same ghost $\mathrm{Cu}$ peak was observed at $\sim 507 \mathrm{eV}$ as mentioned above about the oxygen adsorption measurements. Importantly, in spite of the well-known reactivity of metallic cerium, the $\mathrm{O}(\mathrm{He})$ peak was very small, undetectable on the majority of spectra (Fig. 2(a)), indicating the almost complete lack of oxygen containing contaminants $\left(\mathrm{CO}, \mathrm{H}_{2} \mathrm{O}\right)$ during these measurements. 

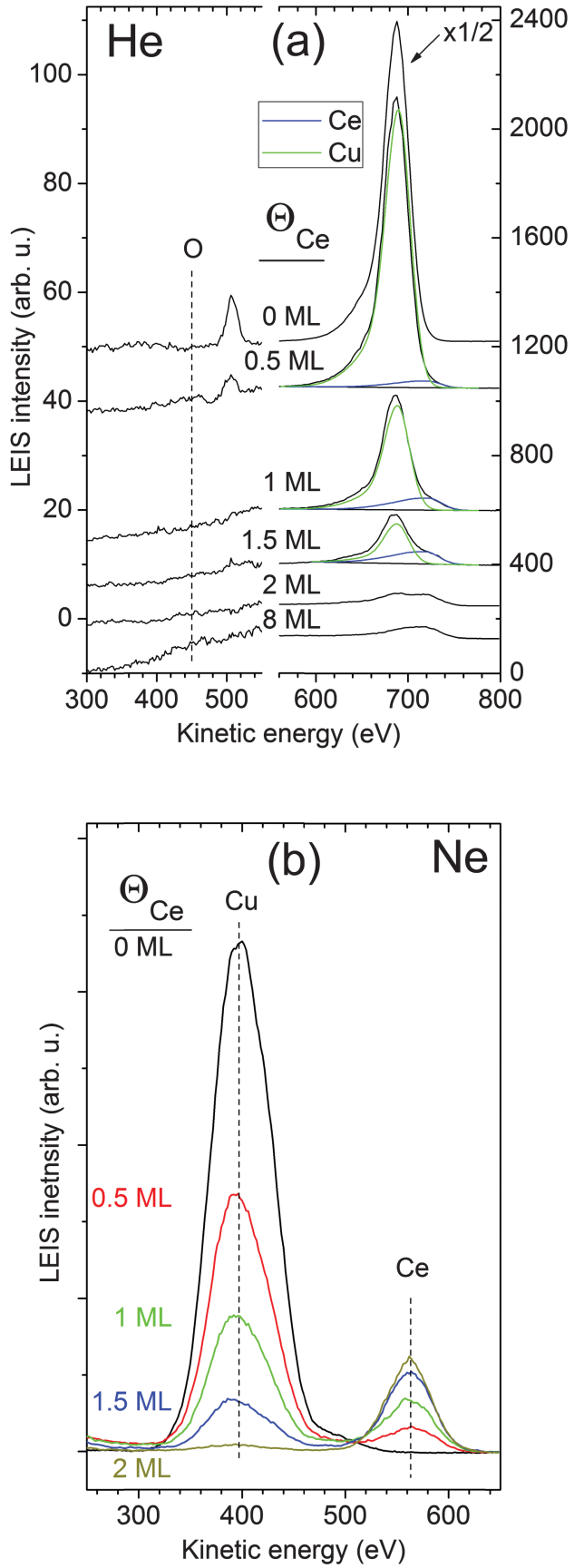

Fig. 2 LEIS spectra obtained with $\mathrm{He}(\mathrm{a})$ and $\mathrm{Ne}(\mathrm{b})$ after depositing $\mathrm{Ce}$ on the $\mathrm{Cu}(111)$ surface at $300 \mathrm{~K}$. Each dose of Ce was evaporated on a clean Cu surface. Note that the vertical scale for the low kinetic energy part of (a) is 20 times more sensitive than the scale for the higher kinetic energy part. In addition, the Cu peak of the clean $\mathrm{Cu}(111)$ surface $(0 \mathrm{ML})$ in (a) is reduced by a factor of 2 .

Since the $\mathrm{Cu}(\mathrm{He})$ peak overlaps the $\mathrm{Ce}(\mathrm{He})$ component, peak fitting was performed. The peak areas obtained with $\mathrm{He}$ and $\mathrm{Ne}$ as a function of Ce coverage are shown in Fig. 3(a) and (b), respectively.

The observed $\mathrm{Ce}(\mathrm{He})$ peak was rather small even at $\Theta_{\mathrm{Ce}}=8 \mathrm{ML}$, when the $\mathrm{Cu}(\mathrm{He})$ peak was completely suppressed by the cerium overlayer. This fact indicates that LEIS with He is much more sensitive to $\mathrm{Cu}$ than to $\mathrm{Ce}$. Under our experimental
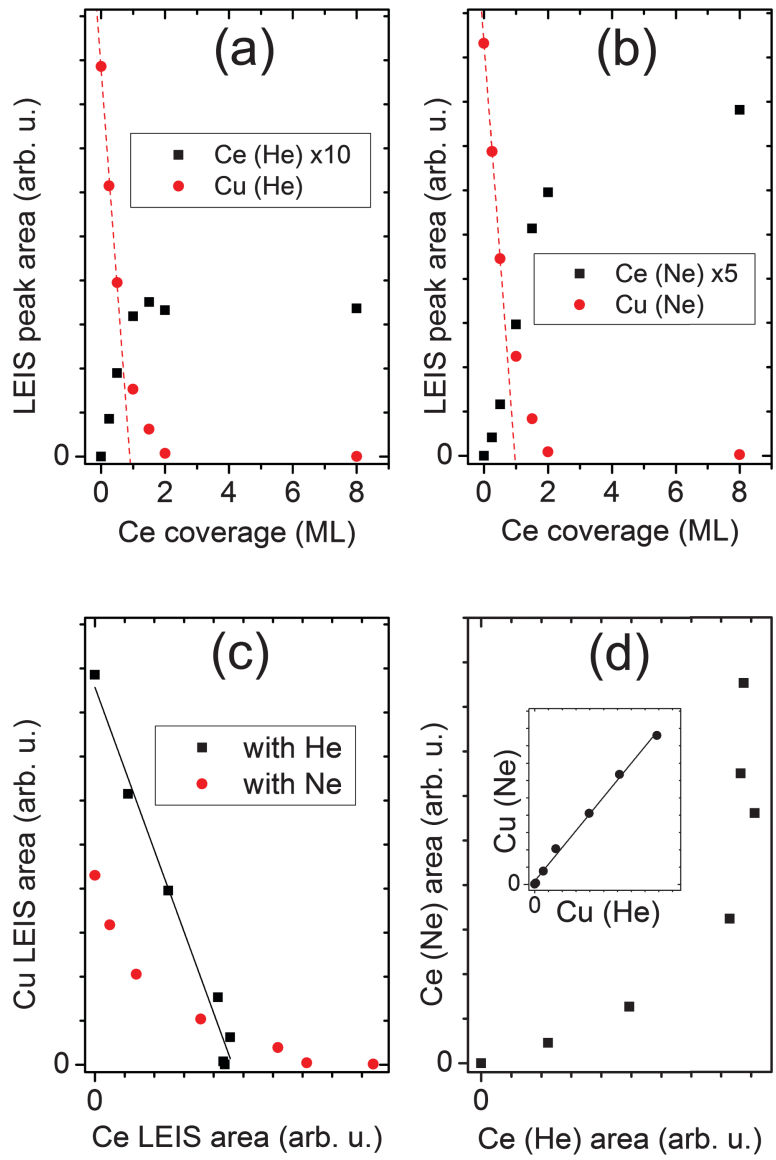

Fig. 3 The change of $\mathrm{Ce}$ and Cu LEIS peak area obtained with $\mathrm{He}(\mathrm{a})$ and $\mathrm{Ne}$ (b) during the deposition of $\mathrm{Ce}$ on $\mathrm{Cu}(111)$ at $300 \mathrm{~K}$. Linear fits on the first three $\mathrm{Cu}$ areas (up to a cerium coverage of $0.5 \mathrm{ML}$ ) are presented as dashed lines for both (a) and (b). In (c) the Cu LEIS area is shown as a function of the $\mathrm{Ce}$ area with both $\mathrm{He}$ and $\mathrm{Ne}$. For the data points obtained with $\mathrm{He}$ a linear fit is also displayed. In (d) the $\mathrm{Ce}(\mathrm{Ne})$ area obtained in the same experiment is plotted against the $\mathrm{Ce}(\mathrm{He})$ area, while in the inset the $\mathrm{Cu}(\mathrm{Ne})$ area is shown as a function of the $\mathrm{Cu}(\mathrm{He})$ area. For the latter a linear fit is also presented.

conditions the difference is a factor of 24. This observation is in line with previous studies reporting the inability in detecting the Ce LEIS peak with He, owing probably to the high neutralization probability. ${ }^{24,35}$ Due to the fact that our scattering angle is relatively small $\left(95^{\circ}\right)$, resulting in higher signal to noise ratios, the Ce peak was well detectable.

In order to check if neutralization effects arose, the Cu LEIS areas are shown as a function of the Ce areas in Fig. 3(c) with both $\mathrm{He}$ and $\mathrm{Ne}$. As apparent from the figure, the $\mathrm{Cu}(\mathrm{He})$ area decreased linearly with the increase in Ce (He) area, implying the absence of neutralization matrix effects for the $\mathrm{Ce} / \mathrm{Cu}(111)$ system when using helium. Consequently, the $\mathrm{Ce}(\mathrm{He})$ area and the decrease in the $\mathrm{Cu}(\mathrm{He})$ area are proportional to the number of cerium atoms in the topmost atomic layer, allowing quantitative evaluation of our data. From the slope of the $\mathrm{Cu}(\mathrm{He}) v s$. $\mathrm{Ce}(\mathrm{He})$ straight line the relative sensitivity factor for Ce was calculated to be $S_{\mathrm{Ce}}=0.0416$. On the other hand, the $\mathrm{Cu}(\mathrm{Ne}) v s$. $\mathrm{Ce}(\mathrm{Ne})$ curve was clearly nonlinear, strongly suggesting a change 
in the $\mathrm{Ne}^{+}$neutralization probability either on $\mathrm{Cu}$ or on $\mathrm{Ce}$ as a function of cerium coverage. Here we suggest a simple way, how to discriminate between these two cases. In Fig. 3(d) the Ce (Ne) area is shown as a function of the Ce (He) area. From Fig. 3(c) it was deduced that the $\mathrm{Ce}(\mathrm{He})$ area is proportional to the fraction of the surface covered by Ce. For this reason, if an analogue proportionality holds for the $\mathrm{Ce}(\mathrm{Ne})$ area, then the $\mathrm{Ce}$ (Ne) vs. Ce (He) curve must be linear. However, a strong nonlinearity can be observed in Fig. 3(d), leading us to conclude that indeed a neutralization matrix effect exists for the $\mathrm{Ce}(\mathrm{Ne})$ signal. Consequently, the $\mathrm{Ce}(\mathrm{Ne})$ area is not proportional to the number of Ce atoms in the outermost atomic layer. On the other hand, the $\mathrm{Cu}(\mathrm{Ne})$ vs. $\mathrm{Cu}(\mathrm{He})$ curve is linear (inset of Fig. 3(d)), implying that the change in the $\mathrm{Cu}(\mathrm{Ne})$ signal is proportional to the fraction of the surface covered by $\mathrm{Ce}(\mathrm{Ne})$. Consequently, while the $\mathrm{Cu}(\mathrm{Ne})$ peak can be used for quantitative analysis of the $\mathrm{Ce} / \mathrm{Cu}(111)$ system, it is not the case for the $\mathrm{Ce}(\mathrm{Ne})$ peak.

Once we determined our limits in the quantitative applicability of LEIS on $\mathrm{Ce} / \mathrm{Cu}(111)$, we turn our attention to the growth of $\mathrm{Ce}$ on $\mathrm{Cu}(111)$. At small Ce coverages $\mathrm{Ce}(\mathrm{He}), \mathrm{Cu}(\mathrm{He})$ and $\mathrm{Cu}(\mathrm{Ne})$ areas all change linearly as a function of Ce dose, as shown by the linear fits in Fig. 3(a) and (b). Remarkably, the extrapolation of the linear decrease of the $\mathrm{Cu}$ peaks crosses the abscissa at $\sim \Theta_{\mathrm{Ce}}=1 \mathrm{ML}$ with both He and Ne. This observation has two implications: (i) the growth is two-dimensional (2D) at small coverages, up to $\Theta_{\mathrm{Ce}}=0.5 \mathrm{ML}$; (ii) there is no significant diffusion of $\mathrm{Ce}$ into the subsurface of $\mathrm{Cu}(111)$ at room temperature in this coverage range.

Increasing the Ce coverage above $0.5 \mathrm{ML}$ leads to a deviation from the linear behaviour of the $\mathrm{Cu}(\mathrm{He})$ and $\mathrm{Cu}(\mathrm{Ne})$ areas (Fig. 3(a) and (b)). Consequently, Ce does not grow layer-bylayer on $\mathrm{Cu}(111)$. The observed non-linearity can be assigned either (i) to the onset of $3 \mathrm{D}$ growth already in this submonolayer coverage range (Stranski-Krastanov growth), or (ii) to an intermixing of $\mathrm{Cu}$ and Ce layers. The $\mathrm{Cu}(\mathrm{He})$ and $\mathrm{Cu}(\mathrm{Ne})$ peaks almost completely disappeared at $\Theta_{\mathrm{Ce}}=2 \mathrm{ML}$ (Fig. 2 and 3).

As was mentioned in the Introduction, significant intermixing of $\mathrm{Ce}$ and $\mathrm{Cu}$ was found on a $\mathrm{Cu}$ film. ${ }^{33}$ There are, however, much less defects on our $\mathrm{Cu}(111)$ surface compared to a film, which may lead to stronger kinetic hindrance for inward diffusion of Ce. Note that after an initial 2D growth, the incorporation of $\mathrm{Rh}$ into the Ce overlayer was detected during the deposition of Ce on $\mathrm{Rh}(111)$ at room temperature. ${ }^{35}$

\section{The interaction of $\mathrm{O}_{2}$ and $\mathrm{Ce}$ on $\mathrm{Cu}(111)$}

In relation to the oxygen-cerium interaction on $\mathrm{Cu}(111)$, we first investigated the effect of $\mathrm{O}_{2}$ adsorption on the $\mathrm{Cu}(111)$ surface partially covered by Ce at room temperature. The comparison of LEIS spectra collected before and after oxygen adsorption demonstrates that the interaction with oxygen enhances the 3D character (i.e. the average height) of Ce clusters on $\mathrm{Cu}(111)$ : exposure to oxygen led to an increase in the $\mathrm{Cu}$ peak, while the presence of oxygen on cerium resulted in the diminution of the Ce peak (Fig. 4). Note that the $\mathrm{O}_{2}$ exposure applied here (1 L) induced only a slight decrease (by $10 \%$ ) in the $\mathrm{Cu}(\mathrm{He})$ peak, when oxygen was dosed on the pure $\mathrm{Cu}(111)$ (Fig. 1).

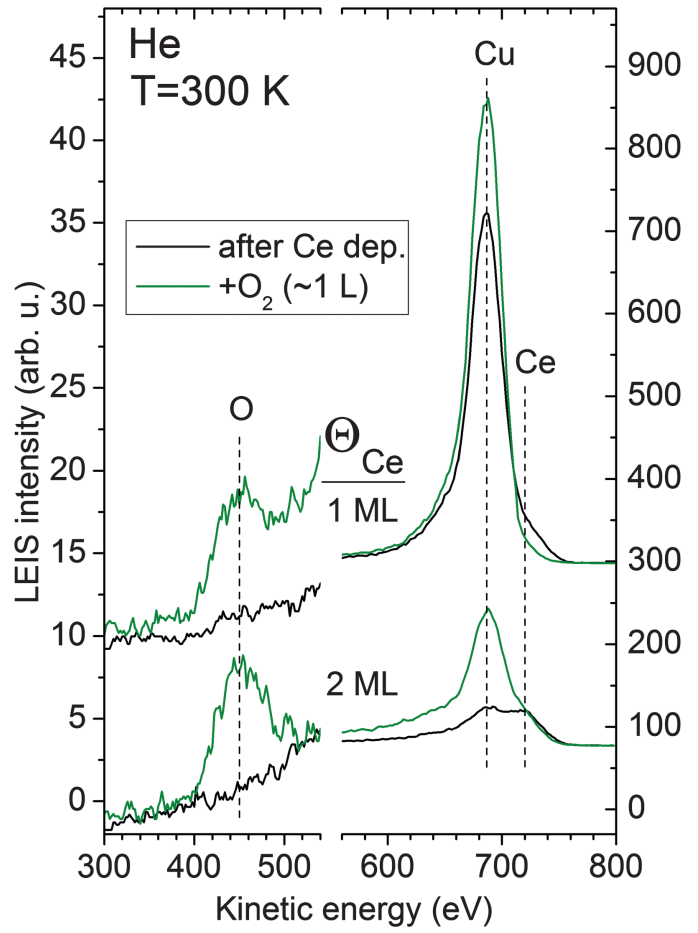

Fig. 4 LEIS spectra obtained with $\mathrm{He}$ after the deposition of $\mathrm{Ce}$ on $\mathrm{Cu}(111)$ at $300 \mathrm{~K}$ and after subsequent adsorption of $\mathrm{O}_{2}(\sim 1 \mathrm{~L})$ at $300 \mathrm{~K}$.

In the next experiment $\mathrm{CeO}_{2}$ was deposited on $\mathrm{Cu}(111)$ evaporating $\mathrm{Ce}$ at a substrate temperature of $523 \mathrm{~K}$ in a background of $\mathrm{O}_{2}$. A similar recipe was frequently applied in previous studies, yielding oriented $\mathrm{CeO}_{2}$ (111) films. ${ }^{20,21}$ However, in our experiment a somewhat higher oxygen pressure was used $\left(3 \times 10^{-6}\right.$ mbar instead of $5 \times 10^{-7}$ mbar $)$ in order to further improve the stoichiometry. LEIS peak areas obtained with He are shown in Fig. 5(a) as a function of $\mathrm{CeO}_{2}$ coverage.

At the initial phase of deposition, up to a $\mathrm{CeO}_{2}$ coverage of $\sim 0.3 \mathrm{ML}$, a very steep decrease in the $\mathrm{Cu}$ component, and an increase in the $\mathrm{O}$ peak were observed, while the Ce contribution was still rather small. In this coverage range the adsorption of oxygen on $\mathrm{Cu}(111)$ is the dominating process. At higher Ce doses both $\mathrm{Cu}$ and $\mathrm{O}$ areas decreased, in parallel to the gradual enhancement of the Ce area (Fig. 5(a)), as the fraction of the surface covered by $\mathrm{CeO}_{2}(111)$ increased. In Fig. 5(b) the fraction of the surface covered by $\mathrm{Cu}$ and $\mathrm{O}$, calculated with the relative sensitivity factor obtained above for $\mathrm{O}\left(S_{\mathrm{O}}\right)$ in the $\mathrm{O}_{2}$ adsorption measurement, is shown as a function of the Ce (He) area. The linear behaviour indicates the absence of neutralization effects for the $\mathrm{Cu}-\mathrm{O}-\mathrm{Ce}$ ternary system, when using $\mathrm{He}$. The applicability of the relative sensitivity factors $S_{\mathrm{O}}$ and $S_{\mathrm{Ce}}$ to the ternary system was checked controlling the fulfilment of the balance (inset of Fig. 5(b)):

$$
1=\zeta_{\mathrm{Cu}}+\zeta_{\mathrm{O}}+\zeta_{\mathrm{Ce}}=\frac{A_{\mathrm{Cu}}+\frac{A_{\mathrm{O}}}{S_{\mathrm{O}}}+\frac{A_{\mathrm{Ce}}}{S_{\mathrm{Ce}}}}{A_{\mathrm{Cu}}(0)}
$$

The agreement was reasonably good, within $10 \%$, in the whole $\mathrm{CeO}_{2}$ coverage range investigated. 

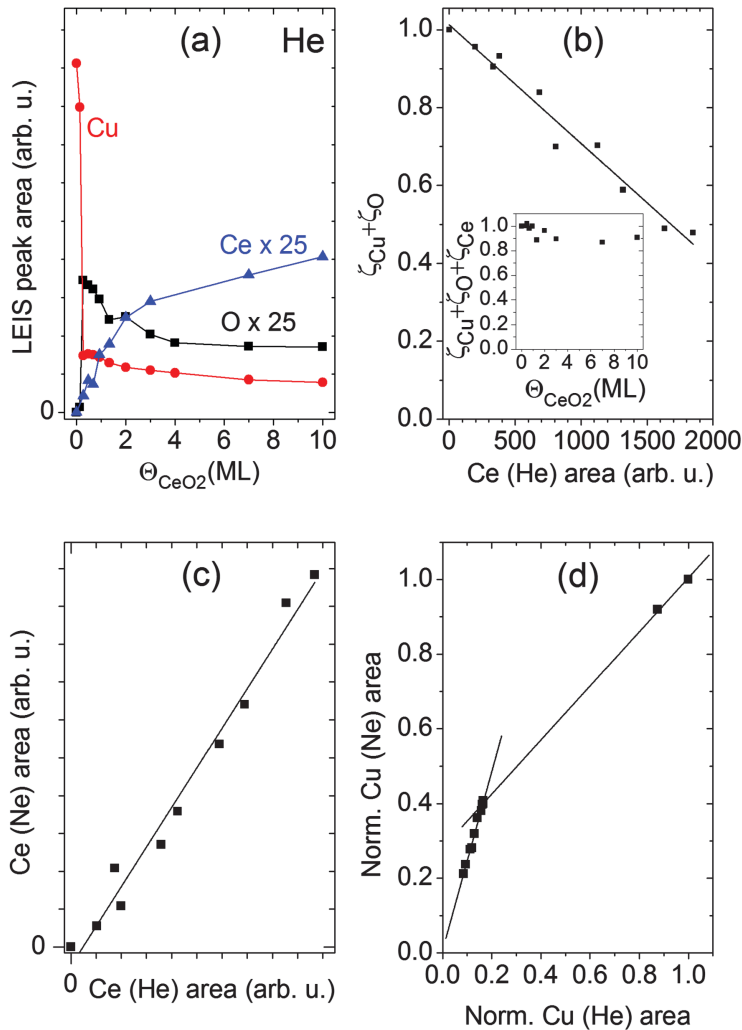

Fig. 5 Deposition of $\mathrm{Ce}$ on $\mathrm{Cu}(111)$ at $T=523 \mathrm{~K}$ in an $\mathrm{O}_{2}$ background of $3 \times 10^{-6}$ mbar, (a) areas of LEIS peaks obtained with $\mathrm{He}$ as a function of $\mathrm{CeO}_{2}$ coverage, (b) the fraction of the surface covered by $\mathrm{Cu}$ and $\mathrm{O}$, calculated using the relative sensitivity factor $S_{O}=0.0191$, displayed as a function of the $\mathrm{Ce}(\mathrm{He})$ area. Inset: $\zeta_{\mathrm{Cu}}+\zeta_{\mathrm{O}}+\zeta_{\mathrm{Ce}}$ as a function of $\mathrm{CeO}_{2}$ coverage, (c) the $\mathrm{Ce}$ area obtained with neon as a function of $\mathrm{Ce}$ area obtained with helium, (d) the normalized $\mathrm{Cu}$ area obtained with neon as a function of the normalized Cu area obtained with helium. For (b), (c) and (d) linear fits are also presented.

Interestingly, the neutralization matrix effect, observed for the Ce peak with neon during the deposition of metallic Ce, did not arise when $\mathrm{CeO}_{2}$ was grown on the copper surface. This is demonstrated by the linearity of the $\mathrm{Ce}(\mathrm{Ne}) v s$. Ce (He) curve presented in Fig. 5(c), and very probably can be attributed to the changes in the valence of $\mathrm{Ce}$. The normalized $\mathrm{Cu}(\mathrm{Ne})$ area displayed as a function of the normalized $\mathrm{Cu}(\mathrm{He})$ area can be well fitted with a broken line (Fig. 5(d)). The slope $(0.72)$ in the region of higher copper intensities agrees well with the slope (0.67) obtained for the $\mathrm{Cu}(\mathrm{Ne}) v s$. $\mathrm{Cu}(\mathrm{He})$ curve in the $\mathrm{O}_{2}$ adsorption measurement (Fig. 1(d)). This coincidence can be understood considering that in the initial phase of $\mathrm{CeO}_{2}$ deposition the attenuation of the $\mathrm{Cu}$ intensities is mostly due to the adsorption of oxygen. At later stages of the growth a further decrease in the $\mathrm{Cu}$ peaks is caused by the formation of $3 \mathrm{D} \mathrm{CeO}_{2}$ particles.

During our experiments about $\mathrm{CeO}_{2}(111)$ deposition, some variation was observed in the wetting of the $\mathrm{Cu}(111)$ surface by the ceria layer. This is in part reasonable, since the $\mathrm{CeO}_{2}(111) /$ $\mathrm{Cu}(111)$ system is thermodynamically of non-wetting nature, and slight changes in the experimental conditions can result in measurable differences in the film morphology. For this
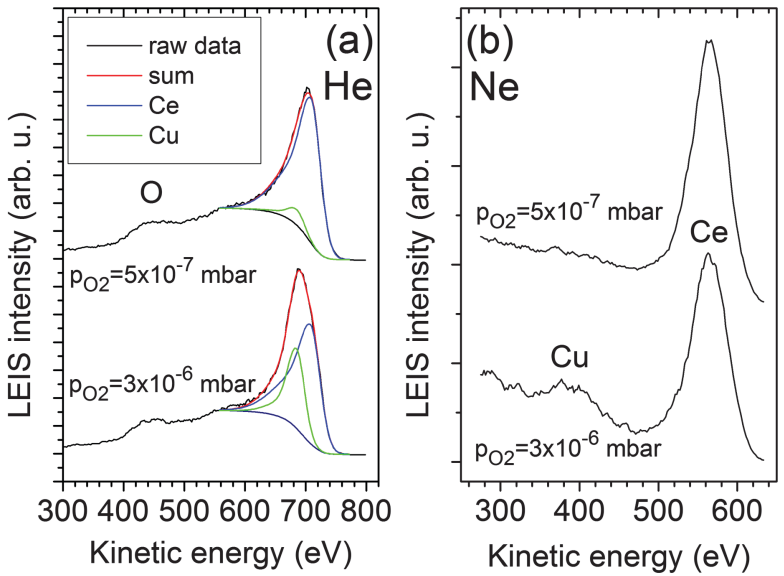

Fig. 6 LEIS spectra obtained with (a) He, and (b) Ne after the deposition of $16 \mathrm{ML}$ of $\mathrm{CeO}_{2}$ on $\mathrm{Cu}(111)$ at different $\mathrm{O}_{2}$ pressures.

reason, in situ monitoring of film continuity by LEIS proved to be very useful. The applied oxygen partial pressure had a well detectable impact on the tightness of the film. $\mathrm{CeO}_{2}(111)$ growth was monitored at two oxygen pressures: $5 \times 10^{-7} \mathrm{mbar}$, and $3 \times 10^{-6}$ mbar. Typical LEIS spectra obtained with He and $\mathrm{Ne}$ after the deposition of $16 \mathrm{ML}$ of $\mathrm{CeO}_{2}$ on $\mathrm{Cu}(111)$ are presented in Fig. 6.

Apparently, while at the preparation pressure of $3 \times 10^{-6} \mathrm{mbar}$ a small $\mathrm{Cu}$ peak $(\sim 0.015 \mathrm{ML})$ was typically observed, the application of the lower pressure led to the almost complete disappearance of copper from the outermost atomic layer $(\sim 0.003 \mathrm{ML}$ detected). The observed $\mathrm{Ce}(\mathrm{Ne}) / \mathrm{Ce}(\mathrm{He})$ area ratios agreed well with the slope of Fig. 5(c).

The better wetting achieved at the lower oxygen pressure, however, was accompanied by a slightly worse stoichiometry, as deduced from Ce 3d XPS spectra, shown in Fig. 7(a). As known from the literature, the $\mathrm{Ce} 3 \mathrm{~d}$ peak shape of $\mathrm{CeO}_{2}$ can be approximated with six peaks, due to shake-down processes involving the valence region, while the Ce $3 \mathrm{~d}$ peak shape of $\mathrm{Ce}_{2} \mathrm{O}_{3}$ can be fitted with 4 peaks. ${ }^{18,46,47}$ For a more detailed picture, which might allow a deeper understanding of the core levels and the properties of Ce in these spectra, we refer to ref. 48 . While at $p_{\mathrm{O}_{2}}=3 \times 10^{-6} \mathrm{mbar} 2 \%$ of cerium ions were in the $3+$ oxidation state, at $p_{\mathrm{O}_{2}}=5 \times 10^{-7}$ mbar this value increased to $4 \%$. In accordance with previous results an asymmetry for the lowest binding energy doublet for $\mathrm{CeO}_{2}$ was allowed in the fitting. ${ }^{49,50}$ The reducing effect of the $\mathrm{Ne}^{+}$dose used for one LEIS spectrum was also checked by XPS. The observed change in the $\mathrm{Ce} 3 \mathrm{~d}$ region was near the limit of detection: the $\mathrm{Ce}^{3+} / \mathrm{Ce}_{\text {total }}$ ratio increased by about $0.5-1 \%$. A LEIS spectrum with $\mathrm{Ne}^{+}$was collected before each spectrum of Fig. 7(a). The applied oxygen pressure had also a significant impact on the oxidation state of the uncovered copper surface/the copper ceria interface as well. It is well-known that the identification of various oxidation states of copper is much easier if the $\mathrm{Cu}$ LMM Auger region of the XPS spectrum is also considered, ${ }^{51}$ as the shift of the $\mathrm{Cu} 2 \mathrm{p}_{3 / 2}$ peak is very small upon oxidation of metallic $\mathrm{Cu}$ to $\mathrm{Cu}_{2} \mathrm{O}$. 

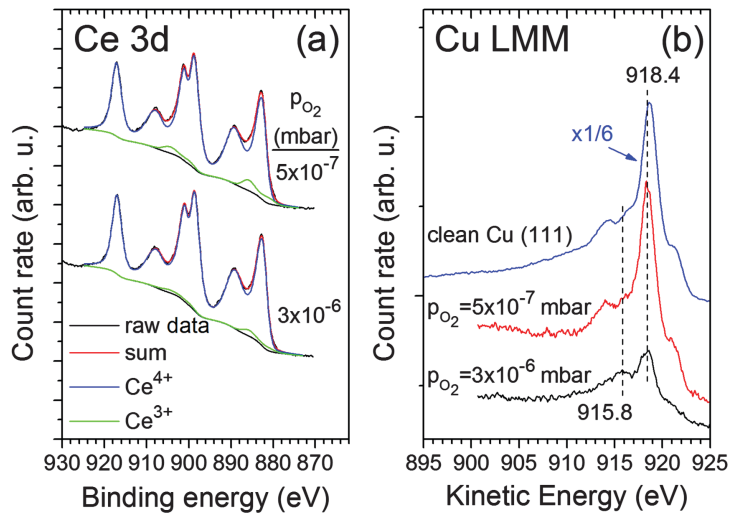

Fig. 7 The Ce $3 d$ XPS region (a) and the Cu LMM Auger region (b) after the deposition of $16 \mathrm{ML}$ of $\mathrm{CeO}_{2}$ on $\mathrm{Cu}(111)$ at varying $\mathrm{O}_{2}$ pressures. In (b) the $\mathrm{Cu}$ LMM region for the clean $\mathrm{Cu}(111)$ surface is also presented.

The $\mathrm{Cu}$ LMM region for the clean $\mathrm{Cu}(111)$ surface and for the $16 \mathrm{ML} \mathrm{CeO}_{2} / \mathrm{Cu}(111)$ film obtained with different oxygen pressures is shown in Fig. 7(b). At the lower pressure the peak shape was very similar to the metallic one, but at $p_{\mathrm{O}_{2}}=3 \times 10^{-6} \mathrm{mbar}$ a relatively strong feature appeared at $915.8 \mathrm{eV}$, which is assigned to $\mathrm{Cu}^{1+}$. We cannot exclude that at $p_{\mathrm{O}_{2}}=3 \times 10^{-6}$ mbar a part of copper ions are accumulated on top of the $\mathrm{CeO}_{2}$ film, possibly in the form of a mixed oxide, since $\mathrm{Ne}^{+}$sputtering led to the disappearance of the $\mathrm{Cu}(\mathrm{He})$ and $\mathrm{Cu}(\mathrm{Ne})$ LEIS peaks and to the attenuation of $\mathrm{Cu} 2 \mathrm{p}$ and $\mathrm{Cu}$ LMM features in the XPS spectrum, accompanied by a more metallic character in the $\mathrm{Cu}$ LMM region (not shown). Since the recipe at $p_{\mathrm{O}_{2}}=5 \times 10^{-7} \mathrm{mbar}$ is identical to the one applied in previous studies, where the oriented growth of $\mathrm{CeO}_{2}(111)$ on $\mathrm{Cu}(111)$ was demonstrated, ${ }^{20,21}$ very probably the same $(1.5 \times 1.5)$ epitaxy holds also for our case.

\section{Conclusions}

The controlled growth of metallic Ce and $\mathrm{CeO}_{2}$ was studied on $\mathrm{Cu}(111)$ by LEIS and XPS. Special attention was paid to the occurrence of neutralization effects, which would significantly hinder quantitative evaluation of LEIS data.

(i) No neutralization effects were identified related to the adsorption of $\mathrm{O}_{2}$ on $\mathrm{Cu}(111)$.

(ii) As regards the interaction of metallic $\mathrm{Ce}$ and $\mathrm{Cu}(111)$, no neutralization effects were observed when using $\mathrm{He}^{+}$, but they arose for the Ce peak collected with $\mathrm{Ne}^{+}$. The initial growth mode of Ce is two dimensional up to $\Theta_{\mathrm{Ce}}=0.5 \mathrm{ML}$, but nearly total coverage of the copper surface is achieved only at $\Theta_{\mathrm{Ce}}=2 \mathrm{ML}$.

(iii) The $\mathrm{CeO}_{2}$ overlayer was prepared evaporating $\mathrm{Ce}$ in an $\mathrm{O}_{2}$ background. No neutralization effects were observed either with helium or neon. The growth mode is three dimensional. LEIS proved to be very efficient in checking the continuity of the ceria films, which was investigated at two different oxygen pressures. At $p_{\mathrm{O}_{2}}=3 \times 10^{-6} \mathrm{mbar}$ the film was not completely closed even at relatively large coverages $(16 \mathrm{ML})$, and a significant part of copper atoms were oxidized to $\mathrm{Cu}^{1+}$. Deposition of $\mathrm{CeO}_{2}$ at $p_{\mathrm{O}_{2}}=5 \times 10^{-7}$ mbar was characterized by a nearly perfect wetting, with metallic copper atoms at the interface, but the stoichiometry of the ceria layer was slightly more reduced.

\section{Acknowledgements}

This work was supported by the Alexander von Humboldt Foundation within the Research Group Linkage Programme, by the Hungarian Scientific Research Fund (OTKA) through the K81660 project, and by COST Action CM1104.

\section{Notes and references}

1 Catalysis by Ceria and Related Materials, Catalytic Science Series, ed. A. Trovarelli and P. Fornasiero, Imperial College Press, London, 2nd edn, 2013, vol. 12, pp. 1-888.

2 J. Llorca, J.-A. Dalmon, P. R. de la Piscina and N. Homs, Appl. Catal., A, 2003, 243, 261.

3 C. Sun, H. Li and L. Chen, Energy Environ. Sci., 2012, 5, 8475.

4 L. Óvári, S. Krick Calderon, Y. Lykhach, J. Libuda, A. Erdőhelyi, C. Papp, J. Kiss and H.-P. Steinrück, J. Catal., 2013, 307, 132.

5 Z. Ferencz, A. Erdőhelyi, K. Baán, A. Oszkó, L. Óvári, Z. Kónya, C. Papp, H.-P. Steinrück and J. Kiss, ACS Catal., 2014, 4, 1205.

6 G. A. Deluga, J. R. Salge, L. D. Schmidt and X. E. Verykios, Science, 2004, 303, 993.

7 S. D. Park, J. M. Vohs and R. J. Gorte, Nature, 2000, 404, 265.

8 H.-J. Freund, Surf. Sci., 2002, 500, 271.

9 U. Diebold, Surf. Sci. Rep., 2003, 48, 53.

10 Q. Fu and T. Wagner, Surf. Sci. Rep., 2007, 11, 431.

11 L. Óvári, L. Bugyi, Z. Majzik, A. Berkó and J. Kiss, J. Phys. Chem. C, 2008, 112, 18011.

12 L. Óvári, A. Berkó, N. Balázs, Z. Majzik and J. Kiss, Langmuir, 2010, 26, 2167.

13 A. Berkó, N. Balázs, G. Kassab and L. Óvári, J. Catal., 2012, 289, 179.

14 D. R. Mullins, P. V. Radulovic and S. H. Overbury, Surf. Sci., 1999, 429, 186.

15 J.-L. Lu, H.-J. Gao, S. Shaikhutdinov and H.-J. Freund, Surf. Sci., 2006, 600, 5004.

16 A. Siokou and R. M. Nix, J. Phys. Chem. B, 1999, 103, 6984.

17 V. Matolín, J. Libra, I. Matolínová, V. Nehasil, L. Sedláček and F. Šutara, Appl. Surf. Sci., 2007, 254, 153.

18 F. Šutara, M. Cabala, L. Sedláček, T. Skála, M. Škoda, V. Matolín, K. C. Prince and V. Cháb, Thin Solid Films, 2008, 516, 6120.

19 T. Staudt, Y. Lykhach, L. Hammer, M. A. Schneider, V. Matolín and J. Libuda, Surf. Sci., 2009, 603, 3382.

20 F. Dvořák, O. Stetsovych, M. Steger, E. Cherradi, I. Matolínová, N. Tsud, M. Škoda, T. Skála, J. Mysliveček and V. Matolín, J. Phys. Chem. C, 2011, 115, 7496.

21 V. Matolín, I. Matolínová, F. Dvořák, V. Johánek, J. Mysliveček, K. C. Prince, T. Skála, O. Stetsovych, N. Tsud, M. Václavů and B. Šmíd, Catal. Today, 2012, 181, 124.

22 R. Wrobel, Y. Suchorski, S. Becker and H. Weiss, Surf. Sci., 2008, 602, 436. 
23 F. Yang, J. Graciani, J. Evans, P. Liu, J. Hrbek, J. F. Sanz and J. A. Rodriguez, J. Am. Chem. Soc., 2011, 133, 3444.

24 M. Alexandrou and R. M. Nix, Surf. Sci., 1994, 321, 47.

25 F. H. P. M. Habraken, E. P. Kieffer and G. A. Bootsma, Surf. Sci., 1979, 83, 45.

26 F. Solymosi and J. Kiss, Surf. Sci., 1981, 104, 181.

27 F. Jensen, F. Besenbacher, E. Lægsgaard and I. Stensgaard, Surf. Sci., 1991, 259, L774.

28 F. Jensen, F. Besenbacher and I. Stensgaard, Surf. Sci., 1992, 269/270, 400 .

29 T. Matsumoto, R. A. Bennett, P. Stone, T. Yamada, K. Domen and M. Bowker, Surf. Sci., 2001, 471, 225.

30 A. Önsten, M. Göthelid and U. O. Karlsson, Surf. Sci., 2009, 603, 257.

31 T. Ďuchoň, F. Dvořák, M. Aulická, V. Stetsovych, M. Vorokhta, D. Mazur, K. Veltruská, T. Skála, J. Mysliveček, I. Matolínová and V. Matolín, J. Phys. Chem. C, 2014, 118, 357.

32 H. H. Brongersma, M. Draxler, M. de Ridder and P. Bauer, Surf. Sci. Rep., 2007, 62, 63.

33 N. A. Braaten, J. K. Grepstad and S. Raaen, Phys. Rev. B: Condens. Matter Mater. Phys., 1989, 40, 7969.

34 P. R. Subramanian and D. E. Laughlin, Bull. Alloy Phase Diagrams, 1988, 9, 322.

35 E. Napetschnig, M. Schmid and P. Varga, Surf. Sci., 2004, $556,1$.

36 D. A. Shirley, Phys. Rev. B: Solid State, 1972, 5, 4709.
37 CRC Handbook of Chemistry and Physics, ed. R. C. Weast and M. J. Astle, CRC Press, Boca Raton, Florida, 60th edn, 1979-1980. 38 Y. Zhao and W. B. Holzapfel, J. Alloys Compd., 1997, 246, 216. 39 P. Kürnsteiner, R. Steinberger, D. Primetzhofer, D. Goebl, T. Wagner, Z. Druckmüllerova, P. Zeppenfeld and P. Bauer, Surf. Sci., 2013, 609, 167.

40 H. Niehus, Surf. Sci., 1983, 130, 41.

41 D. J. Godfrey and D. P. Woodruff, Surf. Sci., 1981, 105, 459.

42 D. J. Godfrey and D. P. Woodruff, Surf. Sci., 1981, 105, 438.

43 E. Platzgummer, M. Borrell, C. Nagl, M. Schmid and P. Varga, Surf. Sci., 1998, 412/413, 202.

44 M. P. Seah and W. A. Dench, Surf. Interface Anal., 1979, 1, 2.

45 J. H. Scofield, J. Electron Spectrosc. Relat. Phenom., 1976, 8, 129.

46 A. Fujimori, Phys. Rev. B: Condens. Matter Mater. Phys., 1983, 28, 4489.

47 A. Pfau and K. D. Schierbaum, Surf. Sci., 1994, 321, 71.

48 C. J. Nelin, P. S. Bagus, E. S. Ilton, S. A. Chambers, H. Kuhlenbeck and H.-J. Freund, Int. J. Quantum Chem., 2010, 110, 2752.

49 T. Skála, F. Šutara, K. C. Prince and V. Matolín, J. Electron Spectrosc. Relat. Phenom., 2009, 169, 20.

50 M. Engelhard, S. Azad, C. H. F. Peden and S. Thevuthasan, Surf. Sci. Spectra, 2004, 11, 73.

51 J. P. Espinós, J. Morales, A. Barranco, A. Caballero, J. P. Holgado and A. R. González-Elipe, J. Phys. Chem. B, 2002, 106, 6921. 